\title{
Synthesis of Spirobicyclic Pyrazoles by Intramolecular Dipolar Cycloadditions/[1s, 5s] Sigmatropic Rearrangements
}

\author{
Christine A. Dimirjian ${ }^{\dagger}$, Marta Castiñeira Reis ${ }^{\dagger}$, Edward I. Balmond, Nolan C. Turman, Elys \\ P. Rodriguez, Michael J. Di Maso, James C. Fettinger, Dean J. Tantillo, Jared T. Shaw \\ Department of Chemistry, University of California, Davis, One Shields Avenue, Davis, California \\ 95616, United States
}

\begin{abstract}
Formation of fused pyrazoles via intramolecular 1,3-dipolar cycloadditions of diazo intermediates with pendant alkynes are described. A subsequent thermal [1s, 5s] sigmatropic shift of these pyrazole systems resulted in a ring contraction to form spirocyclic pyrazoles. The limitations of this rearrangement were explored by chang-ing the substituents on the non-migrating aromatic ring and by using substrates lacking an aromatic linkage to the propargyl group.
\end{abstract}

\section{Keywords}

dipolar cycloaddition; spirocycles; pyrazole; sigmatropic rearrangement

\begin{abstract}
Pyrazoles are common heterocyclic cores in many approved drugs and pharmaceutical lead compounds. ${ }^{1-3}$ The majority of these heterocycles are made by one of two methods: 1) the Knorr condensation of a hydrazine with a 1,3-diketone or 2) dipolarcycloaddition (DPC) of a diazoalkanes with alkynes. ${ }^{4-7}$ Pyrazoles resulting from the latter method with two carbon substituents on an $\mathrm{sp}^{3}$-hybridized carbon adjacent to nitrogen can undergo migration to form either $1 \mathrm{H}$-or $4 \mathrm{H}$-pyrazoles. This process was first noted by van Alphen and the mechanism later explored by Hüttel (Figure 1). ${ }^{8-15}$ The most heavily explored variant involves cyclic acceptor-substituted diazo compounds, which predictably undergo migration of the acyl group to the neighboring nitrogen. ${ }^{16-19}$ Recently, focus has turned to similar migrations of alkyl groups on bicyclic or fused pyrazole systems. ${ }^{17,20-25}$ Padwa showed that spirocyclic pyrazoles could be formed, and then a thermal rearrangement would cause a ring expansion to a fused system. ${ }^{26}$ Valdés has recently explored the migration process in pyrazoles not fused to another ring. ${ }^{20,27}$ Methods to synthesize spiropyrazoles remain limited, with many requiring the use of transition metal catalysts. ${ }^{28-32}$ We discovered an approach to this core structure involving ring contraction following an intramolecular DPC reaction. During the final stages of our work, a similar sequence was reported by Xu using an alternative precursor to the requisite diazo substrates. ${ }^{21}$

During investigations into $\mathrm{C}-\mathrm{H}$ insertion reactions of donor/donor metal carbenes, we noticed a competing pathway of an intramolecular 1,3-dipolar cycloaddition of the diazo
\end{abstract}

$[\dagger]$ These authors contributed equally. 
intermediate in the absence of a rhodium catalyst (Scheme 1). ${ }^{33}$ It was previously known that diazo intermediates could be trapped in the presence of unsaturated alkenes and alkynes. ${ }^{34-38}$ Following our standard procedure, hydrazone $\mathbf{2 a}$ was made by condensing hydrazine onto the corresponding ketone. Once the hydrazone was oxidized by manganese dioxide, the resulting diazo compound (2a') reacted immediately with the propargylic ether (Scheme 1). 39-41 The new cycloaddition product 3a was isolated and the structure was determined by NMR spectroscopy. Compound 3a then underwent partial conversion to 4a during recrystallization at ambient temperature. ${ }^{8-11}$

Computed transition states for the various migration pathways are consistent with the observed ring contraction. In previous studies, similar [1s, $5 \mathrm{~s}]$ sigmatropic shifts proceed to give products of ring expansion. ${ }^{42}$ The rearrangement of $\mathbf{3 a}$ favors formation of the spirobicyclic pyrazole 4a over phenyl migration to either nitrogen or carbon (33 and 34; Figure 2). Results of density functional theory calculations (M062X/6-31+G(d,p $)^{43}$ ) reveal that after the dipolar cycloaddition has taken place, $\mathbf{3 a}$ forms spirocycle 4a with an energy penalty of only $25.3 \mathrm{kcal} / \mathrm{mol}$ (TSBE) compared to the barriers of 27.8 and $31.8 \mathrm{kcal} / \mathrm{mol}$ for TSBC and TSBD, respectively. This preference is likely a result of orbital alignment leading to the newly formed $\sigma$-bond, this alignment is poorest at TSBD where the phenyl substituent migrates towards the nitrogen atom; in this system the phenyl group moves into the plane of the heterocycle rather than migrating over $\mathrm{it}^{44}$.

While the oxidation and DPC reactions occur readily at room temperature, various conditions were explored for the subsequent rearrangement. Heating to $80^{\circ} \mathrm{C}$ for $12-18 \mathrm{~h}$ provided full conversion. The temperature and time required were insensitive to the polarity of the solvent, including protic solvents. Acetonitrile was optimal for solubility and appropriate reflux temperature. These optimized conditions were applied to a variety of substrates (Figure 3). Changing $\mathbf{R}^{\mathbf{2}}$ from a phenyl to methyl (4e and $\mathbf{4 h}$, Figure 3 ) produced only small changes in yield relative to $\mathbf{4 d}$ and $\mathbf{4 g}$, suggesting that this substituent has little impact on the migration step. When a terminal alkyne was used $\left(\mathbf{R}^{\mathbf{2}}=\mathbf{H}\right)$, the rearrangement product $\mathbf{4} \mathbf{c}$ was not stable to purification. When $\mathbf{R}^{\mathbf{1}}$ was changed from $\mathrm{H}$ to $\mathrm{CN}$, the rearrangement proceeded smoothly and the product (4f) was isolated in $88 \%$ yield. Alternatively, when $\mathbf{R}^{\mathbf{1}}$ was changed to $\mathrm{OCH}_{3}$, the terminal alkyne $\left(\mathbf{R}^{\mathbf{2}}=\mathbf{H}\right)$ did not survive the harsher conditions needed for hydrazone formation. Changing the heteroatom from $\mathrm{O}$ to NTs (3a to $\mathbf{3 j}$ ) did not negatively impact the DPC or rearrangement reactions.

Substrates that would produce heterocycles lacking a fused benzene ring were also explored. Although the oxidation and DPC both proceed smoothly, producing $\mathbf{1 6}$ in $71 \%$ yield (Figure 4) as a 91:9 mixture of diastereomers, the rearrangement required much higher temperature when compared to a similar fused substrate (3b). Upon heating to reflux in acetonitrile, only alcohol $19^{45}$ was isolated, which is attributed to the expected rearrangement to $\mathbf{1 7}$ followed by acid-catalyzed hydrolysis via oxocarbenium ion $\mathbf{1 8}$.

Two nitrogen-tethered substrates lacking a fused benzene ring were also investigated (Figure 5). Upon oxidation, sulfonamide 21 underwent facile dipolar cycloaddition, producing 22 in $80 \%$ yield. As with the oxygen-tethered substrate $\mathbf{1 5}$, the subsequent rearrangement proved more difficult. Rearrangement product $\mathbf{2 3}$ was isolated in only $17 \%$ yield from a complex 
mixture of unidentifiable by-products after employing microwave heating in acetonitrile to $150{ }^{\circ} \mathrm{C}$. The addition of various Lewis acids, including $\mathrm{MgBr}_{2}, \mathrm{Sc}(\mathrm{OTf})_{3}, \mathrm{BF}_{3} \bullet \mathrm{OEt}$ and PPTS failed to facilitate the rearrangement at a lower temperature as did the use of several other solvents (methanol, dichloroethane, HFIP and toluene). Substrate 25 was prepared in order to examine the influence of the stereogenic center on the dipolar cycloaddition/ rearrangement sequence. As with previous substrates, the cycloaddition occurred readily upon oxidation of hydrazone $\mathbf{2 5}$ with modest diastereoselectivity favoring cis isomer $\mathbf{2 6 a}$ relative to trans isomer $\mathbf{2 6 b}$. Although 26a is formed via a chair like transition state with the methyl group in an axial position, this transition state structure is predicted to be favored by $1 \mathrm{kcal} / \mathrm{mol}$, since a 1,2 diequatorial interaction of the protecting group and the methyl is avoided. ${ }^{43}$ Isomers $\mathbf{2 6 a}$ and $\mathbf{2 6} \mathbf{b}$ performed differently when heated. Cis isomer 26a did not undergo rearrangement after prolonged heating at $210^{\circ} \mathrm{C}$, whereas trans isomer $\mathbf{2 6 \mathbf { b }}$ behaves similarly to $\mathbf{2 2}$, eventually producing $\mathbf{2 7}$ in modest yield. While the computed barrier for rearrangement of $\mathbf{2 6 \mathbf { a }}$ is higher than that for rearrangement of $\mathbf{2 6 \mathbf { b }}$, these differ by $<1$ $\mathrm{kcal} / \mathrm{mol}$ at the level of theory used, ${ }^{43}$ indicating that either a different method is needed to rationalize the experimental result or the experimental situation is more complicate than expected (e.g., explicit solvent effects are important).

We have discovered a tandem DPC/rearrangement sequence that produces spirocyclic pyrazoles from hydrazone precursors. Although three different rearrangement pathways have been observed with acyclic pyrazoles, we observe only one pathway for substrates with benzene-fused tethers leading to spirocyclic products, which aligns well with computed transition state energies. Substrates derived from benzophenones with a variety of substituents perform well with either oxygen or nitrogen linkages to the pendant alkyne. Substrates leading to spirocycles lacking a fused benzene ring undergo smooth oxidation and dipolar cycloaddition while exhibiting significantly higher barriers to rearrangement.

\section{Experimental Section}

Experimental procedures and compound characterization can be found in the Supporting Information (PDF). ${ }^{1} \mathrm{H}$ and ${ }^{13} \mathrm{C}$ NMR spectra for all new compounds (PDF). X-ray data for compound $4 \mathrm{a}(\mathrm{CIF})$ and $26 \mathrm{a}(\mathrm{CIF})$.

\section{Supplementary Material}

Refer to Web version on PubMed Central for supplementary material.

\section{Acknowledgments}

Research reported in this publication was supported by the National Institute of General Medical Sciences of the National Institutes of Health under Award Number R01GM124234. The contents solely the responsibility of the authors and does not necessarily represent the official views of the National Institutes of Health. Acknowledgment is made to the American Chemical Society Petroleum Research Fund (53767-ND1) for partial support of this research. M.C.R. wants to thank the CESGA (Centro de Supercomputación de Galicia) for the free allocation of computational time and to Carlos Silva López for his helpful discussions. N.C.T. thanks UC Davis for providing a Provost's Undergraduate Fellowship (PUF). We thank the National Science Foundation (CHE1531193) for the Dual source X-ray diffractometer and the XSEDE program (CHE030089) for computational support. 


\section{References:}

(1). Khan MF; Alam MM; Verma G; Akhtar W; Akhter M; Shaquiquzzaman M Eur. J. Med. Chem 2016, 120, 170-201. [PubMed: 27191614]

(2). Xu Z; Gao C; Ren Q-C; Song X-F; Feng L-S; Lv Z-S Eur. J. Med. Chem 2017, 139, 429-440. [PubMed: 28818767]

(3). Faria JV; Vegi PF; Miguita AGC; dos Santos MS; Boechat N; Bernardino AM R. Bioorg. Med. Chem 2017, 25 (21), 5891-5903.

(4). Singh MS; Chowdhury S; Koley S Tetrahedron 2016, 72 (13), 1603-1644.

(5). Fustero S; Sánchez-Roselló M; Barrio P; Simón-Fuentes A Chem. Rev 2011, 111 (11), 69847034. [PubMed: 21806021]

(6). Kempson J In Name React. Heterocycl. Chem. II; John Wiley \& Sons, Inc., 2011; pp 317-326.

(7). Yoon J-Y; Lee S; Shin H Curr. Org. Chem 2011, 15 (5), 657-674.

(8). Hüttel R; Riedl J; Martin H; Franke K Chem. Ber 1960, 93 (6), 1425-1432.

(9). Hüttel R; Franke K; Martin H; Riedl J Chem. Ber 1960, 93 (6), 1433-1446.

(10). van Alphen J Recl. des Trav. Chim. des Pays-Bas 2010, 62 (7), 485-490.

(11). van Alphen J Recl. des Trav. Chim. des Pays-Bas 2010, 62 (7), 491-496.

(12). Jefferson EA; Warkentin JJ Org. Chem 1994, 59 (2), 455-462.

(13). Jefferson EA; Warkentin JJ Am. Chem. Soc 1992, 114 (16), 6318-6325.

(14). Majchrzak MW; Jefferson E; Warkentin JJ Am. Chem. Soc 1990, 112 (6), 2449-2451.

(15). Franck-Neumann M; Dietrich-Buchecker C Tetrahedron Lett 1976, No. 24, 2069-2072.

(16). Yamazaki T; Shechter H Tetrahedron Lett. 1972, 13 (44), 4533-4536.

(17). Jones GW; Chang KT; Shechter HJ Am. Chem. Soc 1979, 101 (14), 3906-3916.

(18). Vuluga D; Legros J; Crousse B; Bonnet-Delpon D Green Chem. 2009, 11 (2), 156-159.

(19). Wu LL; Ge YC; He T; Zhang L; Fu XL; Fu HY; Chen H; Li RX Synthesis 2012, 44 (10), 15771583.

(20). Pérez-Aguilar MC; Valdés C Angew. Chem. Int. Ed 2015, 54 (46), 13729-13733.

(21). Zheng Y; Qiu L; Hong K; Dong S; Xu X Chem. Eur. J 2018, 24 (26), 6705-6711. [PubMed: 29110367]

(22). Hirakawa K; Minami Y; Hayashi SJ Chem. Soc. Perkin Trans 1 1982, No. 0, 577-579.

(23). Braun S; Sturm V; Runzheimer K-O Chem. Ber 1988, 121 (5), 1017-1019.

(24). Huisgen R; Reissig HU; Huber HJ Am. Chem. Soc 1979, 101 (13), 3647-3648.

(25). Mataka S; Ohshima T; Tashiro MJ Org. Chem 1981, 46 (20), 3960-3964.

(26). Padwa A; Woolhouse AD; Blount JJ J. Org. Chem 1983, 48 (7), 1069-1074.

(27). Pérez-Aguilar MC; Valdés C Angew. Chem. Int. Ed 2013, 52 (28), 7219-7223.

(28). Masumoto E; Maruoka H; Okabe F; Fujioka T; Yamagata KJ Heterocycl. Chem 2015, 52 (1), 4853.

(29). Zheng H; Zhu Y; Shi Y Angew. Chem. Int. Ed 2014, 53 (42), 11280-11284.

(30). Yoon H; Rölz M; Landau F; Lautens M Angew. Chem. Int. Ed 2017, 56 (36), 10920-10923.

(31). Pérez-Gómez M; García-López JA Angew. Chem. Int. Ed 2016, 55 (46), 14389-14393.

(32). Zhao HW; Li B; Pang HL; Tian T; Chen XQ; Song XQ; Meng W; Yang Z; Zhao Y. Di; Liu ,YY Org. Lett 2016, 18 (4), 848-851. [PubMed: 26853121]

(33). Soldi C; Lamb KN; Squitieri RA; González-López M; Di Maso MJ; Shaw JT J. Am. Chem. Soc 2014, 136 (43), 15142-15145. [PubMed: 25308822]

(34). Quiclet-Sire B; Zard SZ Chem. Commun 2006, No. 17, 1831.

(35). Zheng Y; Zhang X; Yao R; Wen Y; Huang J; Xu XJ Org. Chem 2016, 81 (22), 11072-11080.

(36). Divya KVL; Meena A; Suja TD Synthesis 2016, 48 (23), 4207-4212.

(37). Liu P; Xu QQ; Dong C; Lei X; Lin GQ Synlett 2012, 23 (14), 2087-2092.

(38). Vuluga D; Legros J; Crousse B; Bonnet-Delpon D Green Chem. 2009, 11 (2), 156-159.

(39). Morrison H; Danishefsky S; Yates PJ Org. Chem 1961, 26 (7), 2617-2618. 
(40). Severin T; Pehr H Chem. Ber 1979, 112 (11), 3559-3565.

(41). Lévesque É; Laporte ST; Charette AB Angew. Chem. Int. Ed 2017, 56 (3), 837-841.

(42). Pérez-Aguilar MC; Valdés C Angew. Chem. Int. Ed 2015, 54 (46), 13729-13733.

(43). Information., S. S. .

(44). See Supporting Information Section 6A2, Figure 2 for further details.

(45). Wei W; Tang Y; Zhou Y; Deng G; Liu Z; Wu J; Li Y; Zhang J; Xu S Org. Lett 2018, 20 (20), 6559-6563. [PubMed: 30284840] 
van Alphen(1943)/Huttel (1960)<smiles></smiles>

Padwa (1980)<smiles>[R]C1=NN([R])C(=O)C1=N</smiles>

Xu (2018)

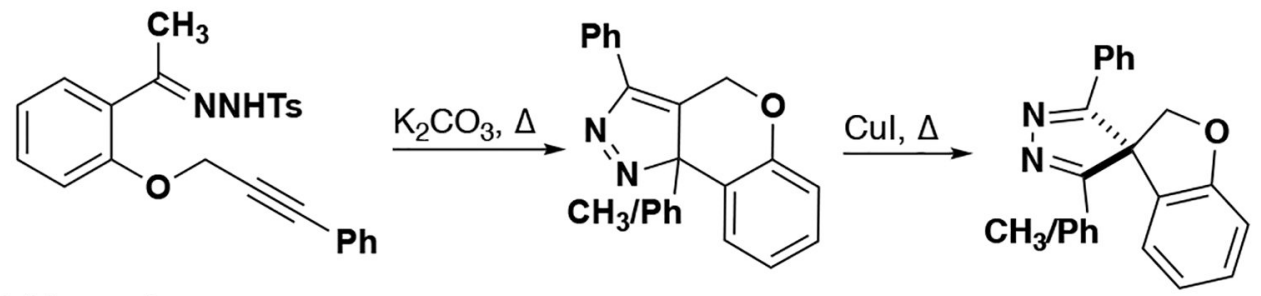

This work<smiles>[R]C#CCOc1ccccc1/C(Br)=N/N</smiles><smiles>[R]C1=C2COc3ccccc3[C@@]2([Al])N=N1</smiles><smiles>[R7]C1=NN=[Te]C12COc1ccccc12</smiles>

Figure 1.

Dipolar cycloaddition rearrangement reactions. 


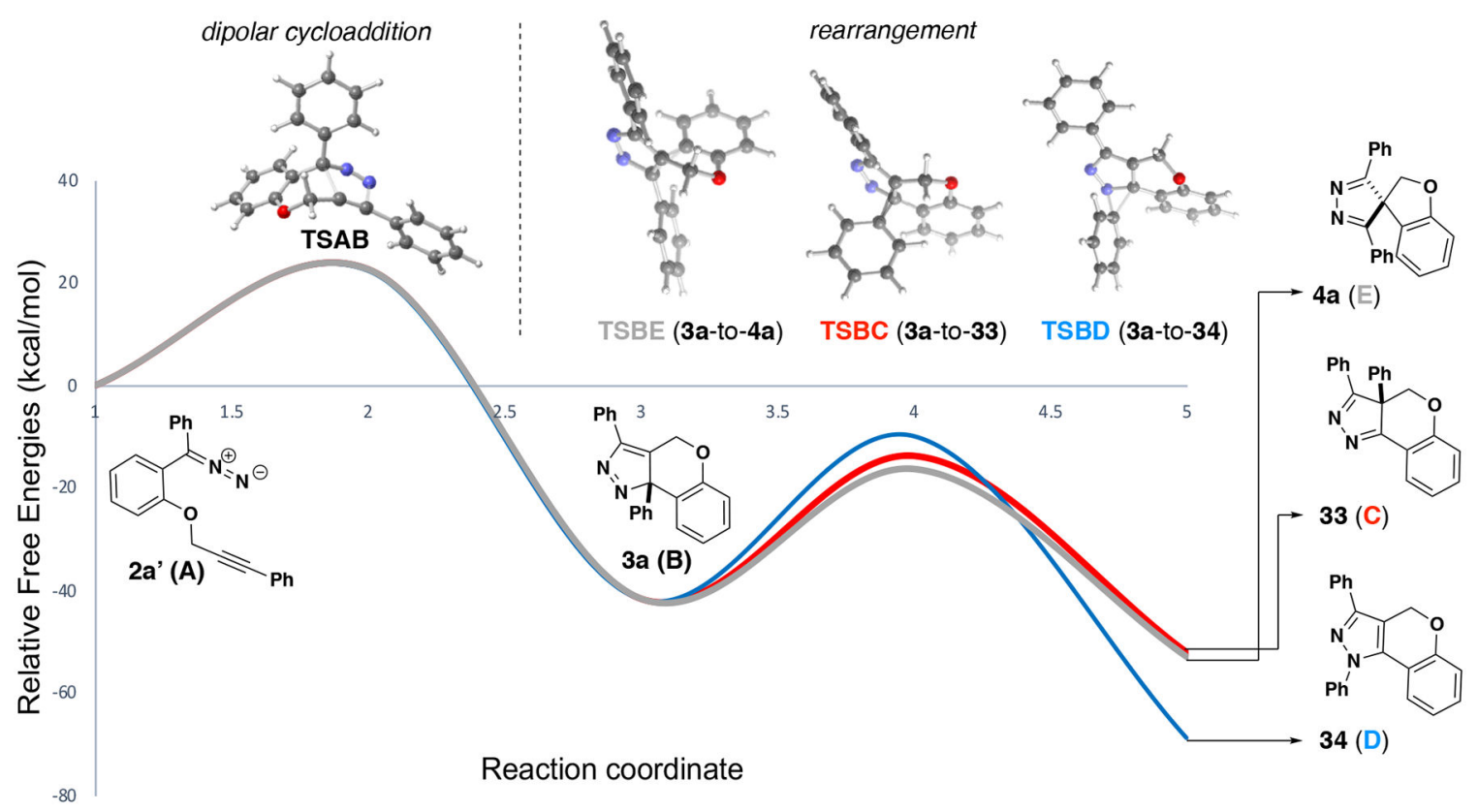

Figure 2.

Predicted (M062X/6-31+G(d,p)) reaction profile for compound 2a', based on free energies of minima and transition state structures. 
<smiles></smiles>

2a-i $(X=0)$

2j (X=NTs)<smiles>[R7]C1=C2CCC3(CCCCC3)C2(c2ccccc2[X])N=N1</smiles>

3a-i $(X=0)$ 3j $(\mathrm{X}=\mathrm{NTS})$

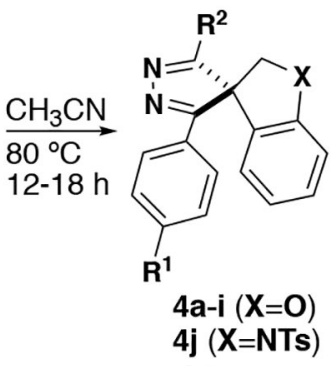

4a-i $(\mathbf{X}=\mathbf{0})$
$4 \mathbf{j}(\mathbf{X = N T s )}$
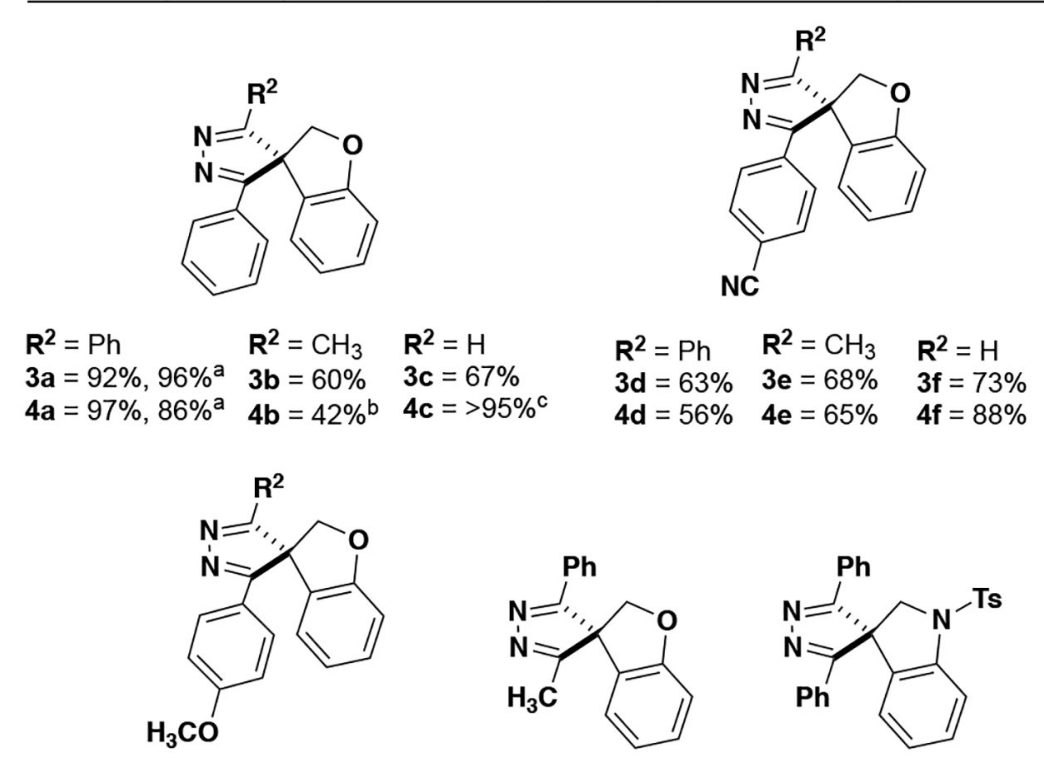

$$
\begin{array}{ll}
\mathbf{R}^{\mathbf{2}}=\mathrm{Ph} & \mathbf{R}^{\mathbf{2}}=\mathrm{CH}_{3} \\
\mathbf{3 g}=66 \% & \mathbf{3 h}=87 \%
\end{array}
$$$$
3 \mathbf{i}=81 \%
$$$$
\mathbf{4 i}=87 \%
$$$$
\mathbf{3} \mathbf{j}=89 \%
$$$$
\mathbf{4 j}=93 \%
$$

a Run on $1 \mathrm{mmol}$ scale. bYield over two-step.

${ }^{6}$ Conversion based on ${ }^{1} \mathrm{H}$ NMR of unpurified reaction mixture.

Figure 3.

Benzophenone derived spiropyrazoles. 


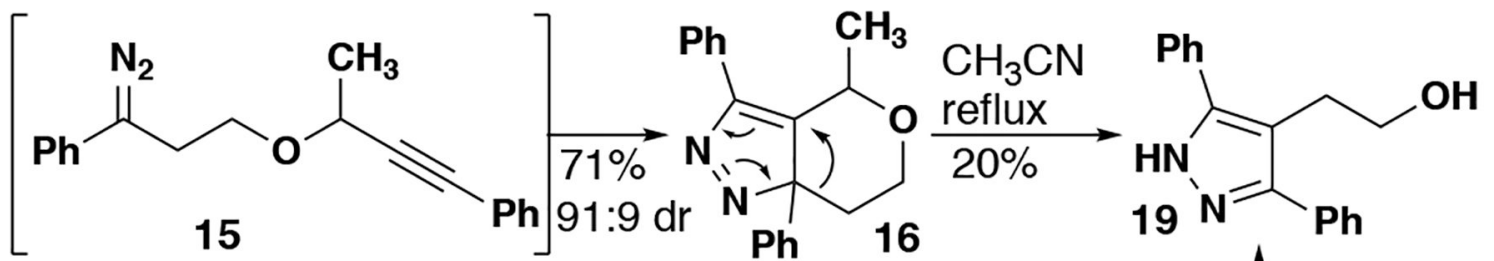

15

Ph 16

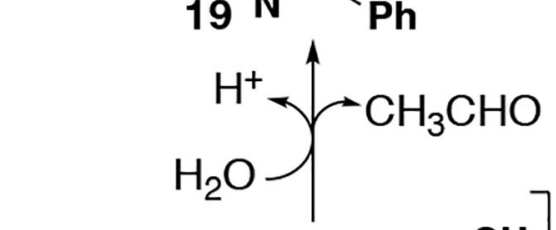<smiles>CC(C#CPc1ccccc1)OCCC(=NN)c1ccccc1</smiles>
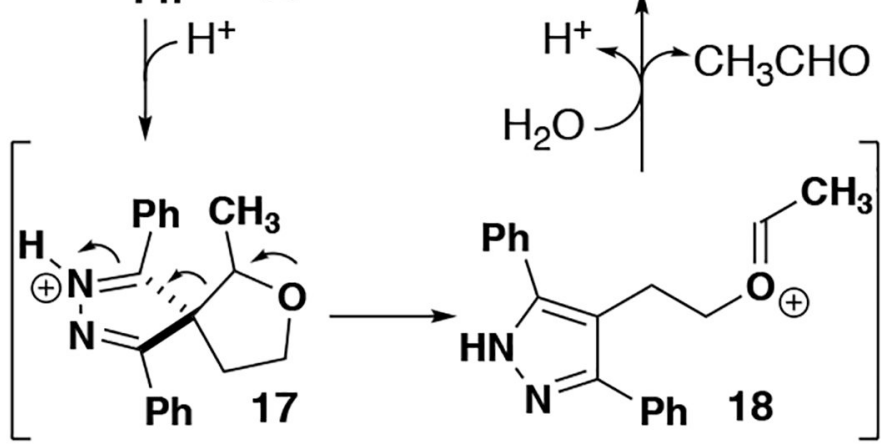

Figure 4.

Oxygen tethered substrate 14 leading to alcohol 19 by rearrangement and hydrolysis after the DPC reaction. 


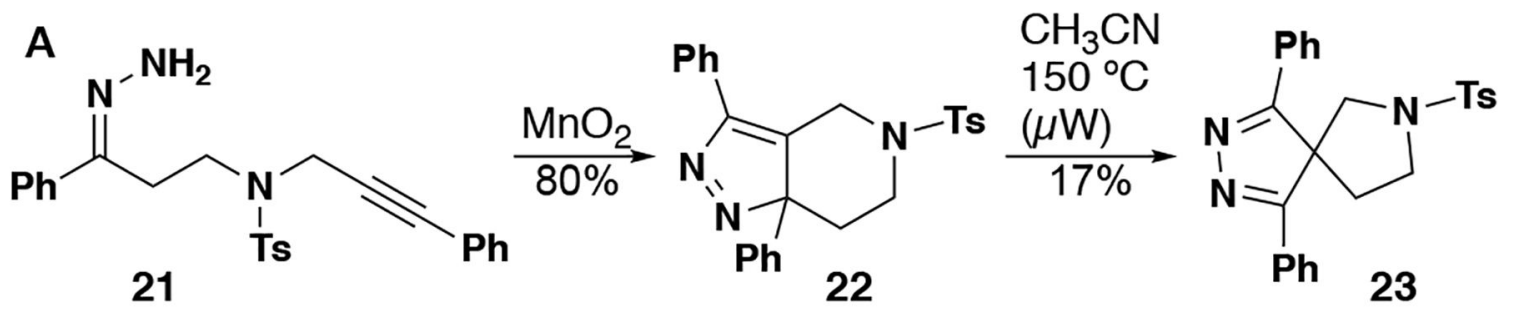

B<smiles>[Y5]N(CC/C(=N/N)OC)C(C)C#CPc1ccccc1</smiles>
25<smiles>[3H]N1CC[C@]2([Pb])N=NC(c3ccccc3)=C2C(C)[C@H]1C</smiles>

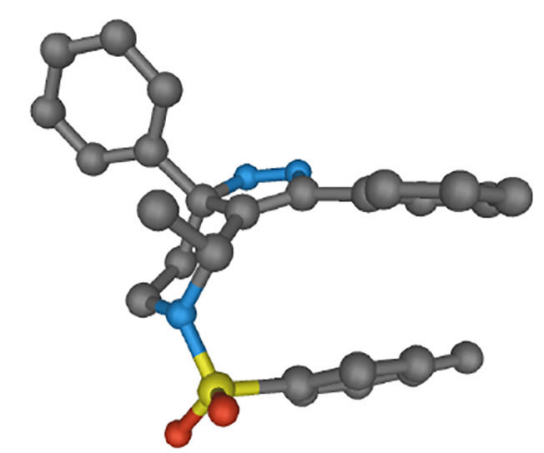

X-ray crystal structure of $\mathbf{2 6 a}$

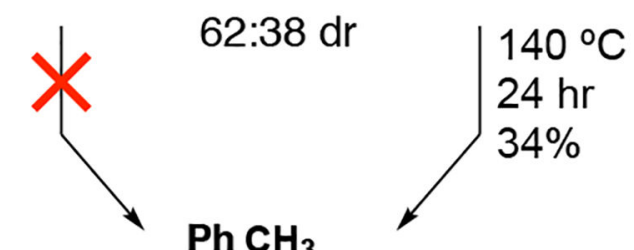

Figure 5.

Nitrogen-tethered substrates leading to spirocyclic pyrrolidines. 


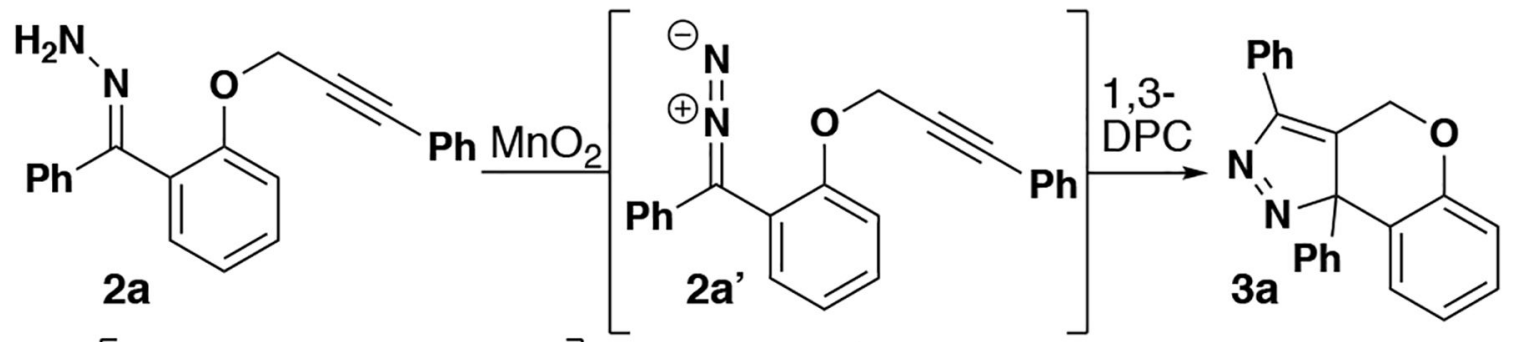

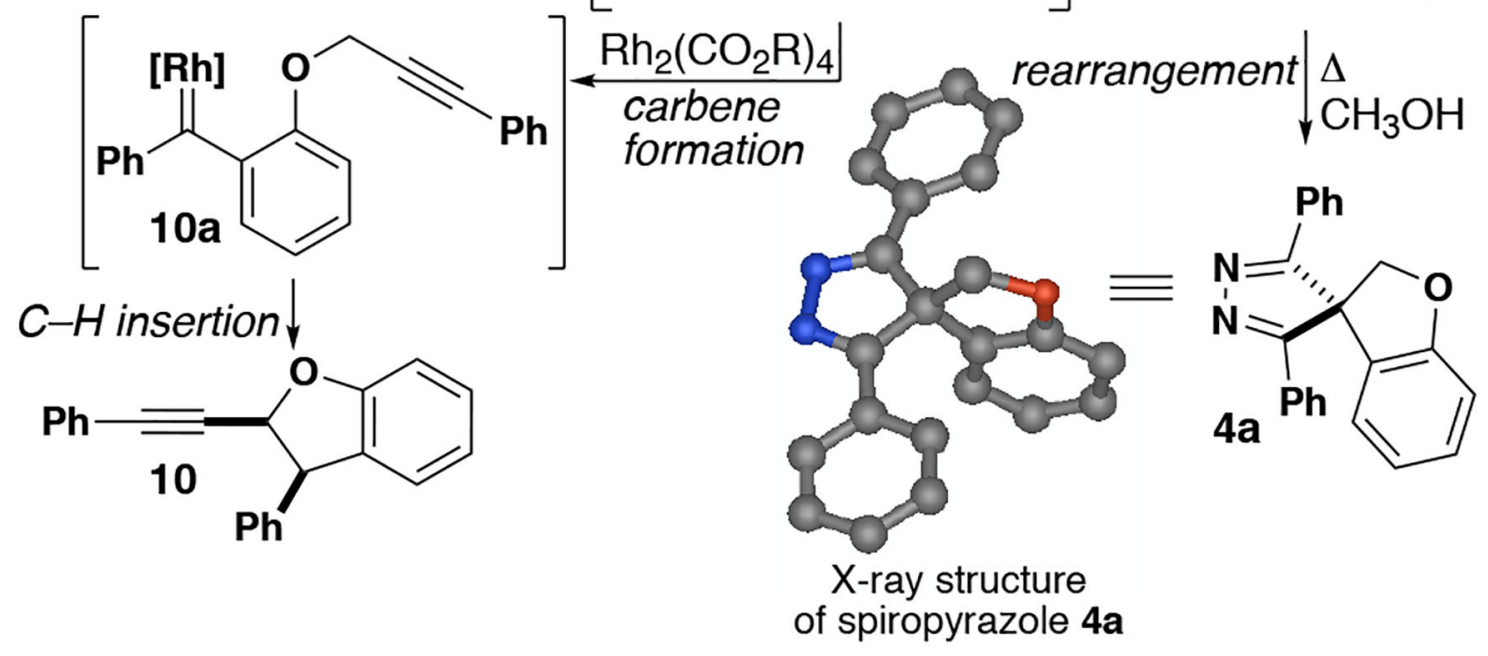

Scheme 1.

Reactions of propargylic hydrazones. 